\title{
Preliminary Analysis on Polycyclic Aromatic Hydrocarbons (PAHs) of Surface Sediment within Eastern Route of China's South-to-North Water Diversion Project_Case of NanSi Lake
}

\author{
Ji-Qing $\mathrm{LI}^{1, a, *}$, Yu-Shan ZHANG ${ }^{2, b}$ and Kai-Jie XIE ${ }^{3, a}$
}

a National Engineering Laboratory for Biomass Power Generation Equipment, North China Electric Power University, Beijing China

b Office of the South-to-North Water Diversion Project Commission of the State Council, Beijing 100053, China

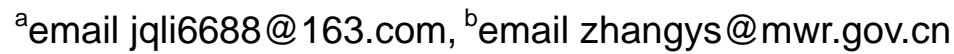

Keywords: Polycyclic Aromatic Hydrocarbons (PAHs); water quality security; Nansi Lake basin; Eastern Route of South-to-North Water Diversion in China

\begin{abstract}
With the implementation of the South-to-North water diversion project in china, water quality problems have become increasingly prominent along the Eastern Route of South-to-North Water Diversion Project, China. As an important water-transfer channel and storage lake for the Eastern Route, the water quality of Nansi Lake has a direct impact on the water quality security of The Eastern Route project. On the basis of measured data and previous research results, this paper has preliminarily analyzed the distribution, content, and changing trend of Polycyclic Aromatic Hydrocarbons (PAHs) of Nansi lake basin in China under the climate change. The analysis results show that the pollution control of Nansi lake basin has achieved significant results in recent years and the water quality is continuously improving, however, there are still some kinds of PAHs which are potentially threatening the diverting water quality of the Eastern Route project. Further effective measures for controlling pollution should be taken in the future along the Eastern Route project to reduce the adverse impact of these PAHs on water quality security.
\end{abstract}

\section{Introduction}

Polycyclic Aromatic Hydrocarbons(PAHs)usually mean the fused ring compounds which contain two or more benzene rings in linear, angular, or cluster-like arrangement. They are a series of persistent organic pollutants (POPs) that exist widely in the environment. These pollutants mainly come from human activities and energy utilization, such as the incomplete combustion of hydrocarbons, waste discharges in the petroleum refining, spills in offshore oil development and petroleum transportation, etc. Polycyclic aromatic persistent organic pollutants have characteristics of hydrophobicity, fat-solubility, semi-volatility, long-range migratory aptitude, high toxicity and high perniciousness, etc. Wang[1]suggests that these pollutants, which are hard to be decomposed for their specific and stable cyclic structure, can remain in the environmental media for several years or even decades or even longer, such as water body[2], soil[3] and substrate sludge, and can also accumulate in plants, animals and human body. Most POPs are carcinogenic, mutagenic and teratogenic, and can cause acute or chronic poisoning. Since 1980s, PAHs in the environmental media have drawn more and more attention[4], and some countries have made a great deal of detailed investigation and assessment on PAHs in sediments of lakes, estuaries, bays, and coastal zones in recent years[5]. In china, researches about the distribution of PAHs and pollution-tracking in some rivers and thalassic sediments have been also reported, such as the South China Sea, Yangtze River estuary and so on[6].

Nansi Lake, which is located in the border region between Jiangsu and Shandong province in the east part of China, is an essential part of Eastern Route of South-to-North Water Diversion Project, and it is also one of the important storage lakes of Eastern Route project, whose water quality has a direct impact on the water quality security of Eastern Route project. Of all the lakes along the Eastern Route of South-to-North Water Diversion Project, Nansi Lake has the worst water quality 
and the most difficult problem of sewage treatment. Over the past few years, more efforts have been made to prevent pollution in Nansi lake drainage area where water quality is continuously becoming better. However, persistent organic pollutants are quite chemically stable and difficult to decompose and degrade, which means they may remain in water, soil and lake sediment for long time. Thus, it is a threat to water quality security of the Eastern Route project. Therefore, the impact of PAHs on water quality in the diversion project should be fully taken into account in the pollution control of the Eastern Route. Based on the previous research, in October 2012, we made a chemical analysis again and preliminarily obtained some information of the distribution, content and changing trend of 16 kinds of EPA-PAHs in Nansi Lake sediments, which is new exploration to the further conduct of water pollution control in Nansi Lake Basin and the safety guarantee of water quality in the Eastern Route project.

\section{Water Environment in Nansi Lake}

Nansi Lake is the biggest freshwater lake in Shandong Province, including four connected lakes, Nanyang Lake, Dushan Lake, Zhaoyang Lake and Weishan Lake, and is divided into superior lake and lower lake by a $2^{\text {nd }}$ level lake hydro Project. It stretches about $120 \mathrm{~km}$ from north to south and $5-25 \mathrm{~km}$ from west to east, and the total catchment is $31700 \mathrm{~km}^{2}$, which includes $8580 \mathrm{~km}^{2}$ of eastern area, $21854 \mathrm{~km}^{2}$ of western area and $1266 \mathrm{~km}^{2}$ of water area. There are 53 rivers flowing into Nansi Lake, including 22 comparatively large rivers, and floods of all the rivers will flow into the sea through Hanzhuang Canal, Zhong requirements of South-to-North Water Diversion Project. Statistics of those key pollution sources along the project route suggest that papermaking, food and beverage sectors and chemical industry take top three positions in COD emission and they account for $62.40 \%, 9.80 \%$ and $8.20 \%$ of the total emission respectively ${ }^{[7]}$. Test of the treated waste water discharged by three typical industries, papermaking, textile printing and dyeing, shows that POPs which are hard to degrade still exist and they'll enter the water and surface sediments to affect the water quality of Nansi Lake to a certain degree.

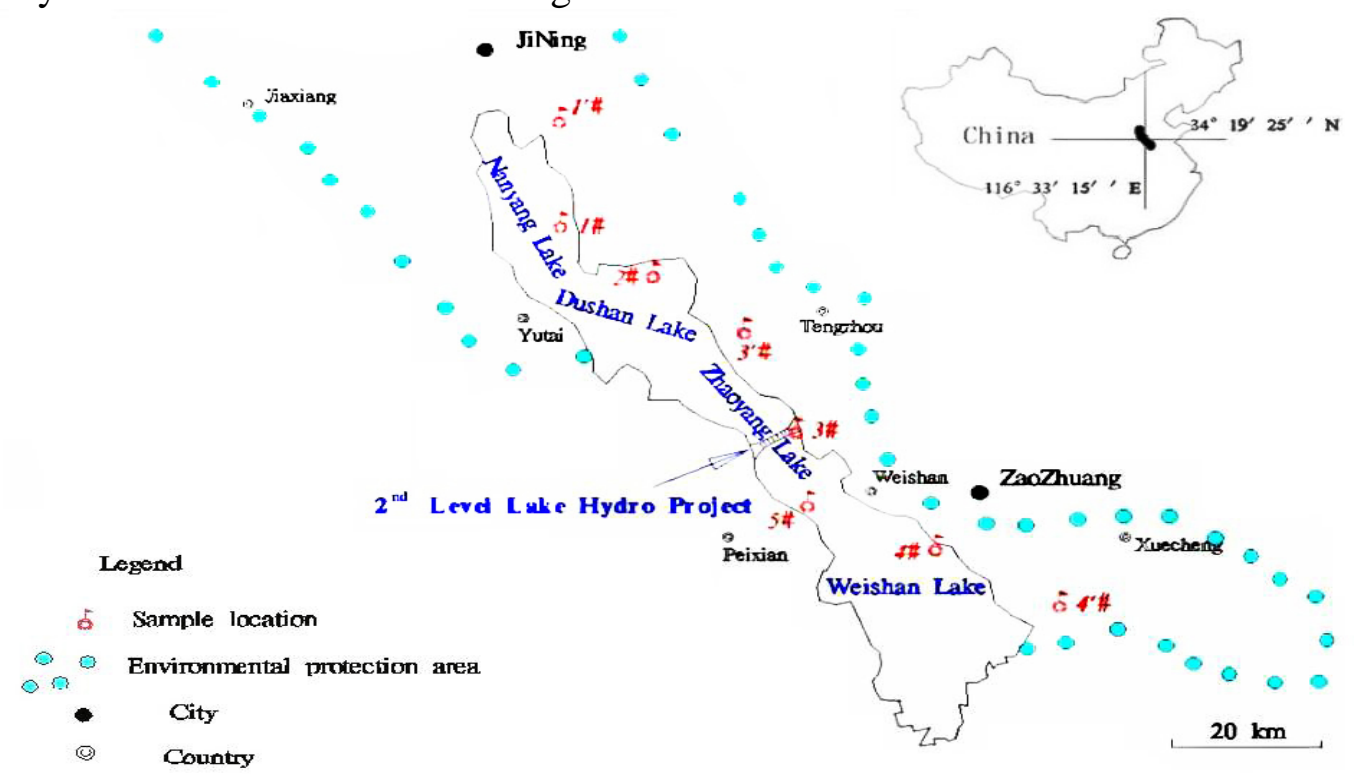

Fig1. Schematic research region and Sampling Location

\section{Sampling and Testing of PAHs in Nansi Lake}

\section{Sampling Stations Layout and Sample Collection}

According to the "Report on the State of the Environment in China from 2004 to 2008" issued by Chinese Environmental Protection Bureau, the water quality of Nansi Lake has always belonged to 
Grade V or been worse than Grade V, which is far from the water quality requirements of South-to-North Water Diversion Project. There are 9 representative Sampling stations in Nansi lake, including five of them from $1 \#$ to $5 \#$ in the Lake District, and four of them from 1'\# to 4'\# in nearby typical rivers flowing into lakes. Fig 1 shows the schematic research region and Sampling locations . In October 2012, we carried out 7 effective samples in 9 sampling stations .The detailed Canal and Xinyi river after regulated.

Table 1 Sampling stations and sample descriptions

\begin{tabular}{|c|c|c|c|c|c|c|}
\hline No. & $\begin{array}{l}\text { Station } \\
\text { location }\end{array}$ & North latitude & East longitude & $\begin{array}{l}\text { Depth of } \\
\text { water(m) }\end{array}$ & Sample description & $\begin{array}{c}\text { Document } \\
\text { number }\end{array}$ \\
\hline $1 \#$ & $\begin{array}{l}\text { Nanyang } \\
\text { Lake }\end{array}$ & $35^{\circ} 7^{\prime} 17.7^{\prime \prime} \mathrm{N}$ & $116^{\circ} 39 ' 52.3^{\prime \prime E}$ & 5.0 & $\begin{array}{l}\text { Cinereous and slants yellow } \\
\text { larger water content }\end{array}$ & $1 \#$ \\
\hline 1 '\# & Baima river & $35^{\circ} 11^{\prime} 48.6^{\prime \prime} \mathrm{N}$ & $116^{\circ} 42^{\prime} 46.5^{\prime \prime} \mathrm{E}$ & 2.0 & $\begin{array}{|lrr|}\text { Dark grey, viscous, larger } \\
\text { water content, nearly no } \\
\text { granular silt }\end{array}$ & -- \\
\hline 2\# & Dushan Lake & $35^{\circ} 4$ '35.6"N & $116^{\circ} 45^{\prime} 6.1^{\prime \prime} \mathrm{E}$ & 3.0 & Dark, viscous & $2 \#$ \\
\hline 2 '\# & Beisha river & $35^{\circ} 2 ' 24.0^{\prime \prime} \mathrm{N}$ & $116^{\circ} 56^{\prime} 44.5^{\prime \prime} \mathrm{E}$ & 0.5 & $\begin{array}{l}\text { shallow water, no-clay; only } \\
\text { hard sands, sewage ditch }\end{array}$ & \\
\hline 3\# & $\begin{array}{l}\text { Zhaoyang } \\
\text { Lake } \\
\end{array}$ & $34^{\circ} 52^{\prime} 38.3^{\prime \prime N}$ & $116^{\circ} 59 ' 36.3 " \mathrm{E}$ & 2.0 & $\begin{array}{l}\text { charcoal grey, thicker, finely } \\
\text { ground particle }\end{array}$ & $\begin{array}{l}2^{\text {nd }} \text { level } \\
\text { lake Dam }\end{array}$ \\
\hline 3'\# & $\begin{array}{l}\text { Chengguo } \\
\text { river }\end{array}$ & $34^{\circ} 56^{\prime} 20.0^{\prime \prime N}$ & $116^{\circ} 57^{\prime} 40.2^{\prime \prime} \mathrm{E}$ & 6.0 & $\begin{array}{l}\text { charcoal grey, thicker, rough } \\
\text { mud pellet, similar to3\# }\end{array}$ & -- \\
\hline $4 \#$ & $\begin{array}{l}\text { Weishan } \\
\text { Lake }\end{array}$ & $34^{\circ} 38^{\prime} 23.5^{\prime \prime N}$ & $117^{\circ} 16^{\prime} 43.5^{\prime \prime} \mathrm{E}$ & 2.5 & close to black, viscous & 4\# \\
\hline $4^{\prime} \#$ & $\begin{array}{l}\text { Hanzhuang } \\
\text { Canal }\end{array}$ & $34^{\circ} 35^{\prime} 44.1^{\prime \prime N}$ & $117^{\circ} 21 ' 38.4^{\prime \prime E}$ & 4.0 & $\begin{array}{|ll|}\begin{array}{l}\text { no-clay,(river cleaned } \\
\text { Recently) }\end{array} & \text { up } \\
\end{array}$ & -- \\
\hline $5 \#$ & $\begin{array}{l}\text { Weishan } \\
\text { Lake }\end{array}$ & $34^{\circ} 41^{\prime} 53.4^{\prime \prime} \mathrm{N}$ & $117^{\circ} 4^{\prime} 15.4^{\prime \prime E}$ & 5.0 & $\begin{array}{l}\text { Yellow-dark colloidal mud, } \\
\text { viscous }\end{array}$ & $\begin{array}{l}\text { Gaolou } \\
\text { Scenic }\end{array}$ \\
\hline es & \multicolumn{6}{|c|}{ : 2 '\#and 4'\# are invalid samples } \\
\hline
\end{tabular}

\section{Sample Testing}

\section{Instruments and Reagents}

Instruments: MARSXPRESS microwave extraction instrument of Ampex U.S.; Agilent 6890-5973 gas chromatograph - mass spectrometer. Reagents: chromatography pure reagents n-hexane of Fisher, U.S., methylene dichloride and acetone, analytical pure reagents anhydrous sodium sulfate, activated silica gel (80-100 mesh), neutral alumina (80-100 mesh); standard samples of PAHs recovery rate indicator: naphthalene-D8 (purchased from American Accustandard company); The PAHs standard materials purchased from American Supelco Corporation.

\section{Extraction}

Sample pretreatment: water content of the samples can be calculated after lyophilization and milled by $2 \mathrm{~mm}$ sieve; Weigh $10 \mathrm{~g}$ of soil, and then add $25 \mu \mathrm{L}$ of $0.02 \mathrm{mg} / \mathrm{mL}$ standard sample of PAHs recovery rate indicator-naphthalene -D8.Extraction procedure: Put the prepared sample into the extraction tin, and then add $25 \mathrm{~mL}$ solvent to do the extraction in microwave extraction instrument. Extraction conditions: the solvent is acetone/ n-hexane $(1: 1, \mathrm{~V} / \mathrm{V}), 25 \mathrm{~mL}$, and the temperature should be $105^{\circ} \mathrm{C}$, then warm for 10 mins, maintain for 10 mins, and cool for 30 mins to room temperature; then conduct rotary evaporation after extraction, concentrating the sample to about 1 $\mathrm{mL}$.

\section{Sample Purification}

Purification reagent pretreatment: anhydrous Na2SO4: dipping into methanol and cleaning with ultrasonic washer for half an hour, Soxhlet extraction in dichloromethane for $72 \mathrm{~h}$, burning for 4 
hours at $450{ }^{\circ} \mathrm{C}$. Activating silica gel: dipping into methanol and cleaning with ultrasonic washer for half an hour, Soxhlet extraction in dichloromethane for 72 hours, activating for 12 hours at $180^{\circ} \mathrm{C}$ and preserved in bottle after getting dry naturally under room temperature. Activating alumina: dipping into methanol and cleaning with ultrasonic washer for half an hour, using Soxhlet extraction in dichloromethane for 72 hours, activating for 12 hours at $250^{\circ} \mathrm{C}$ and preserved in bottle after getting dry naturally under room temperature. Select the glass column with a knob at diameter $1.5 \mathrm{~cm}$, adding absorbent cotton at the bottom, then packing dry column. Firstly, wet with n-hexane $30 \mathrm{~mL}$, then choose the sample, and clean with $30 \mathrm{~mL}$ of n-hexane, remove impurities. Secondly, clean with $150 \mathrm{~mL}$ of dichloromethane, then collect the eluent. Finally concentrate to $5 \mathrm{~mL}$ by rotary evaporation, blow by pressured gas, bring to volume $1 \mathrm{~mL}$ by n-hexane, and put it in the GC-MS sample bottle.

\section{Sample Testing}

DB - 5ms Silica capillary column $(30 \mathrm{~m} \times 0.25 \mathrm{~mm} \times 0.25 \mathrm{um})$. Chromatographic column temperature program: maintain at $60^{\circ} \mathrm{C}$, heating up to $300 \quad{ }^{8} \mathbf{C}$ per5minute, then maintaining $10 \mathrm{~min}$; Inlet temperature at $250{ }^{\circ} \mathrm{C}$; temperament transfer line temperature at $290{ }^{\circ} \mathrm{C}$; flow rate of carrier gas: $1 \mathrm{ml} / \mathrm{min}$; injection mode: splitless $(0.75 \mathrm{~min})$; injection volume: $1 \mathrm{uL}$; mass spectrometry ion source is Electron Impact (EI); electron multiplier voltage is $2893 \mathrm{ev}$; scan mass range (m/ $\mathrm{z}$ ) is 50-350amu; selecting ion monitoring mode.

\section{Quality Assurance and Control}

In order to reduce testing error, we carried out two parallel samples at each station and tested twice in parallel for each sample. Take 3'\# sample as example (shown in Table 2), it adopts deuterated naphthalene as the indicator of recovery rate to control the quality. The result shows that recovery coefficient is between $50.7 \%$ and $68.9 \%$, and relative standard deviation of each parallel sample is between $1.5 \%$ and $5.9 \%$ and all of them meet the requirements.

Table 2 QA/QC report of sample 3"\#

\begin{tabular}{|c|c|c|c|c|c|c|}
\hline \multirow{2}{*}{ PAHs } & \multicolumn{5}{|c|}{ testing result (ng/g) } & average \\
\cline { 2 - 5 } & $\mathbf{1}$ & $\mathbf{2}$ & $\mathbf{3}$ & $\mathbf{4}$ & $\begin{array}{c}\text { RSD } \\
\text { (\%) }\end{array}$ \\
\hline Nap & 35.8 & 36.3 & 31.8 & 33.9 & 34.45 & 5.9 \\
\hline Any & 108.9 & 105.9 & 107.4 & 112.7 & 108.725 & 2.7 \\
\hline Ane & 45.3 & 47.2 & 46.6 & 48.1 & 46.8 & 2.5 \\
\hline Fle & 35.8 & 38.4 & 35.8 & 36.8 & 36.7 & 3.3 \\
\hline Phe & 28.4 & 26.8 & 27.6 & 28.9 & 27.925 & 3.3 \\
\hline Ant & 27.5 & 28.1 & 26.9 & 25.3 & 26.95 & 4.5 \\
\hline Fla & 152.3 & 154.8 & 157.3 & 157.2 & 155.4 & 1.5 \\
\hline Pyr & 14.8 & 14.9 & 15.1 & 16.2 & 15.25 & 4.2 \\
\hline Baa & 70.3 & 68.5 & 71.1 & 72.5 & 70.6 & 2.4 \\
\hline Chr & 15.4 & 16.9 & 15.2 & 14.3 & 15.45 & 7.0 \\
\hline Bbf/Bkf & 140.6 & 138.7 & 142.3 & 144.2 & 141.45 & 1.7 \\
\hline Bap & 28.9 & 28.4 & 30.8 & 31.6 & 29.925 & 5.1 \\
\hline Daa & 31.4 & 30.2 & 32.5 & 31.7 & 31.45 & 3.0 \\
\hline I1p/Bgp & 8.9 & 8.7 & 9.3 & 9.5 & 9.1 & 4.0 \\
\hline
\end{tabular}

\section{Testing Result}

For the 7 effective samples, we tested all the target materials (16 kinds of PAHs-EPA) and the result is illustrated in Table 3. 
Table 3 Testing results of each site sample PAHs

(ng/g)

\begin{tabular}{|c|c|c|c|c|c|c|c|}
\hline PAHs & $\mathbf{1 \#}$ & $\mathbf{1} \#$ & 2\# & 3\# & 3'\# & 4\# & 5\# \\
\hline Nap & ND & ND & ND & ND & 34.5 & ND & ND \\
\hline Any & ND & 101.2 & ND & ND & 108.7 & ND & ND \\
\hline Ane & ND & 44.5 & ND & ND & 46.8 & ND & ND \\
\hline Fle & ND & ND & ND & ND & 36.7 & ND & ND \\
\hline Phe & ND & ND & ND & ND & 27.9 & ND & ND \\
\hline Ant & ND & ND & ND & ND & 26.9 & ND & ND \\
\hline Fla & ND & 155.0 & ND & ND & 155.4 & 9.4 & ND \\
\hline Pyr & 5.8 & 112.7 & 10.3 & 5.4 & 15.3 & 9.0 & 9.5 \\
\hline Baa & ND & 93.5 & 5.2 & ND & 70.6 & ND & ND \\
\hline Chr & 5.3 & ND & 3.1 & 6.7 & 15.5 & 4.2 & 21.2 \\
\hline $\begin{array}{c}\text { Bbf } \\
\text { /Bkf }\end{array}$ & 33.2 & 61.3 & ND & ND & 141.5 & ND & 13.7 \\
\hline Bap & 41.4 & 65.3 & ND & ND & 29.9 & 4.2 & 7.0 \\
\hline Daa & 103.7 & ND & ND & 897.1 & 31.5 & 154.1 & ND \\
\hline $\begin{array}{l}\text { I1p/ } \\
\text { Bgp }\end{array}$ & 68.2 & ND & ND & ND & 34.5 & 136.9 & ND \\
\hline total & 257.6 & 633.5 & 18.6 & 909.2 & 755.5 & 307.2 & 45.4 \\
\hline Note & \multicolumn{7}{|c|}{ ND means not detected, the same below. } \\
\hline
\end{tabular}

As shown in Table 3, we can come to the primary conclusion or suggestions that: Firstly, the total content of PAHs in each station is between 18.6 to $909.2 \mathrm{ng} / \mathrm{g}$ in Nansi Lake, and the content of PAHs in the $2^{\text {nd }}$ level lake dam region(3\# . 3'\# stations) which is located in the middle of the lake is highest , While the southern and northern regions of lake is comparatively low. It means the pollution in central part of Nansi Lake is even worse and we should pay more attention to pollution control in this area. Secondly, the total amount of PAHs in other stations in 2012 is less than that in 2002 in Nansi Lake except $3 \#$ station(the $2^{\text {nd }}$ level dam). On the whole, in recent years, the content of PAHs shows a decreasing trend in Nansi Lake. At the same time, it should also be noted that the total contents of PAHs are still high in some stations (such as 1 \#, 3 \# and 4 \#), and continue to show an upward trend in certain station. (such as 3 \#). Thirdly, the content of PAHs of simple structure is very little in Nansi Lake while in recent years there are some complex polycyclic Aromatic Hydrocarbons coming into existence in some areas and accumulating, and they're still increasing, such as Naphthophenanthrene(a, h), indeno (1,2,3-cd) pyrene and benzo (ghi) perylene. These complex PAHs are more easily accumulated in the surface sediments of lake-bottom due to their high boiling points, and they deserve more attention in pollution control in the future ${ }^{[8]}$.

\section{Conclusion}

On the basis of measured data and previous research results, this paper preliminarily analyzed the distribution, content, and changing trend of PAHs in Nansi lake basin. The current test results show that the pollution control has achieved significant results and the water quality is continuously improving in recent years. But, some PAHs of complex structure still exist which are potentially threatening the water quality of Eastern Route of South-to-North Diversion project. Further effective measures should be taken in the future pollution control work of Eastern Route project to reduce the adverse impact of these kinds of PAHs on water quality security. In addition, this paper measured and analyzed only 7 samples from 9 stations in Nansi Lake, which means the samples are insufficient and we should increase the number of sampling sites, and then thoroughly analyze the 
distribution, content, and changing trend of PAHs of Nansi lake basin, which will help to conduct pollution control in Nansi Lake basin in future.

\section{Acknowledgement}

This research was financially supported by RSRI Open Research Program (CKWV2015232/KY), National key research and development program (2016YFC0402208, 2016YFC0401903) and National Natural Science Foundation of China (No.51641901). We are also grateful to editors and anonymous reviewers.

\section{References}

[1] L.S. Wang, H.X. Chow, S.K. Han. Analysis techniques of PAHs, Nanjing: Nanjing University Press, 1988

[2] A.H. Arias, C.V. Spetter, R.H. Freije, et al. Polycyclic aromatic hydrocarbons in water, mussels (Brachidontes sp., Tagelus sp.) and fish (Odontesthes sp.) from Bahia Blanca Estuary, Argentina. Estuarine, Coastal and Shelf Science. 2009; 85 (1): 67-81

[3] D. Liu, Z.Q. Gong, J.H. Jin, X.J. Li, et al. Degradation of polycyclic aromatic hydrocarbons in industrial and agricultural soils by immobilized Mucor sp. and their bioavailability assessment. 2012, 31 (5): pp 604-609

[4] R. Boonyatumanond, G. Wattayakorn, A. Togo, et al. Distribution and origins of polycyclic Aromatic Hydrocarbons (PAHs) in riverine, estuarine, and marine sediments in Thailand Marine. Pollution Bulletin, Volume 52, Issue 8, August 2006, Pages 942-956

[5] K.F. Chang, G.C. Fang, J.C. Chen, et al. Atmospheric polycyclic Aromatic Hydrocarbons (PAHs) in Asia: A review from 1999 to 2004 Environmental Pollution, Volume 142, Issue 3, August 2006, Pages 388-396

[6] J. Li, G. Zhang, X.D. Li, S.H. Qi, et al. Source seasonality of polycyclic Aromatic Hydrocarbons (PAHs) in a subtropical city, Guangzhou, South China Science of The Total Environment, Volume 355, Issues 1-3, 15 February 2006, Pages 145-155

[7] J.R. Ni, G.D. Ji, T.H. Li. Measurements for control of Nansi Lake region typical polluting industries, Beijing: Peking University, 2008

[8] M.P. Zakaria, H. Takada, S. Tsutsumi, et al. Distribution of Polycyclic Aromatic Hydrocarbons (PAHs) in Rivers and Estuaries in Malaysia: A Widespread Input of Petrogenic PAHs. Environ. Sci. Technol., 2002, 36 (9), pp 1907-1918 